Marriott, H. L. (1947). Brit. med. F. i, 245.

Muller, A. F., Riondel, A. M. \& Mach,'R. S. (1956). Lancet, 270, 83 I.

Nadal, J. W., Pederson, S. \& Maddock, W. G. (194I). F. clin. Invest. 20, 691.

Robinson, J. R. (1957). Proc. Nutr. Soc. 16, 108.

Rowntree, L. G. (1922). Physiol. Rev. 2, r 16.

Widdowson, E. M. (1957). Proc. Nutr. Soc. 16, I 8 .

Wrong, O. (1956). Clin. Sci. I5, 40r.

Wynn, V. (1955). Clin. Sci. 14, 669.

Wynn, V. \& Rob, C. G. (1954). Lancet, 266, 587.

Young, W. F. (1957). Proc. Nutr. Soc. 16, 128.

Zimmerman, B. \& Wangensteen, O. H. (1952). Surgery, 31, 654.

\title{
The restoration and maintenance of water equilibrium in disease
}

\author{
By Winifred F. Young, Queen Elizabeth Hospital for Children, London, E.2
}

The consequences of changes in water equilibrium have been vividly described by previous contributors to this symposium (Robinson, 1957; Elkinton, 1957; Widdowson, 1957; Black, 1957) who have explained to us how both severe depletion and gross expansion of the volume of the body fluids may endanger life itself. Early diagnosis of the diseases likely to cause dehydration can often be made and medical care is easily available in this country. A knowledge of the proper use of water and electrolytes should, therefore, be used mainly for prevention rather than for the treatment of a breakdown of water equilibrium. Unfortunately we are often not quick enough, and severe stages of dehydration may be reached at an alarming speed in very sick patients. Overhydration and water intoxication are usually due to misguided treatment of an individual patient, but the history of events leading up to his clinical state may have been an inadequate guide to his needs. Plans for the management of both depletion and excess must therefore be to hand if successful treatment is to be given when an emergency arises.

\section{Assessment of patient's needs}

The objects of treatment are to restore and maintain the volume, and to repair the composition, of the body fluids. Since water equilibrium is dependent upon the concentration of electrolytes in the extracellular and the intracellular fluids, the requirements of water and salt must be assessed together. The estimate of an individual patient's needs must take into account ( $\mathbf{r})$ the preceding deficit, (2) current normal daily losses from the skin and lungs and in the urine, and (3) concomitant abnormal losses, e.g. from the alimentary tract or in the sweat. At first, the duration, magnitude and probable site of increased losses, or the extent of a deficient intake may be deduced from the history and clinical state. Later, frequent observations of the clinical state of the patient, variations in his body-weight, and recorded estimates of the output of the urine and stools are used to appraise his needs. It is not always easy to obtain information about the urine output in very sick patients and in young children, but experienced nurses are usually able to give a fair account without 
necessarily collecting the full output. Dilute urine from a dehydrated patient or scanty concentrated urine from one receiving a high fluid intake is a valuable early clue to renal dysfunction, which may be due either to primary disease of the kidneys causing the breakdown of water equilibrium, or to some electrolyte imbalance affecting their function, for example salt depletion which has been treated with water but without enough salt.

Abnormal losses from vomiting or duodenal aspiration should be measured if possible, but they do not always represent the actual loss. Pooling of gastro-intestinal secretions deprives the body fluids of a large volume and may be the cause of unexplained recurrences of dehydration without loss of weight; the degree of abdominal distension often does not indicate the full extent of such a pool.

At the beginning of treatment chemical analysis of the serum is usually unnecessary and the results may be misleading as a pointer to the actual needs of the body for rehydration. Thus a dehydrated patient with a history of vomiting and diarrhoea may have high serum sodium and chloride levels but an absolute deficit of sodium chloride which must be replaced as treatment proceeds. Estimation of the plasma electrolytes is much more helpful at later stages of treatment when the volume of the body fluids has been restored, especially in patients with persistingly high abnormal losses in whom the success of attempts to repair the composition of the body fluids is in doubt. Difficulties over treatment are to be expected in patients with intestinal obstruction or paralytic ileus if the function of the bowel is slow to recover, and in those with uncontrollable diarrhoea and vomiting of the severity sometimes encountered in infantile gastro-enteritis.

\section{Treatment}

The management of the majority of patients is easy despite the large element of guesswork often necessary in planning treatment, provided that ( $\mathrm{I}$ ) the circulating blood volume and (2) good renal function are restored early in the course of treatment; and that gross distortion of the composition of the body fluids is avoided by adding suitable amounts of sodium and potassium salts to the solutions being given at appropriate stages. Emphasis is again placed on the importance of establishing a free flow of urine during the treatment of patients suffering both from depletion and from excess. As we have been told by earlier speakers the urine is the main outlet from the pond of extracellular fluid surrounding the cells, and the kidneys, by selective excretion, play an essential part in the readjustment towards the normal distribution and composition of the body fluids. The clinician finding himself challenged to treat a dehydrated patient whose kidneys are unable to play this part, soon appreciates how dependent upon them he has become for the management of dehydration states.

Plans for the treatment of dehydration may be divided into two stages.

(I) Restoration of the circulating blood volume and of a free flow of urine, by rapid administration of fluid.

Few patients are suffering from water deprivation alone, so that solutions of 
sodium salts in dextrose solution (the concentration of salt being varied according to individual need) should usually be given at this stage. In cases of shock, with or without blood loss or manifest leakage of plasma (as in burns), blood or plasma must be given to maintain the circulating blood volume during a critical phase.

Fluids must always be given intravenously to patients with severe degrees of dehydration (in whom the deficit may be assumed to exceed $5 \%$ of the body-weight). With lesser degrees, oral administration may be attempted for patients who can drink without vomiting, or who can tolerate tube feeding. If unsuccessful, the route should be changed before the clinical condition has deteriorated.

(2) Restoration of the volume and distribution of the total body fluids, by giving water and sodium salts in excess of the amounts needed for replacement within the first $24 \mathrm{~h}$., and potassium salts more slowly to begin replacement of the intracellular deficit, or at least to offset concomitant losses.

During the initial period of treatment there is opportunity for observation of the patient in order to assess his rate of loss from the skin and lungs (which, e.g., is increased by pyrexia) and from the gastro-intestinal tract. The estimate of his daily $(24 \mathrm{~h})$ requirements can then be based upon normal requirements, with an added allowance for replacement of any previous deficit and of continuing losses. At this stage potassium salts should usually be added to the solutions of sodium salts and dextrose. A rise in the concentration of potassium in the plasma to 8-ro m-equiv./ 1. (twice the normal level) causes cardiac arrest, and therefore strict precautions must be observed when potassium is being given intravenously. Some clinicians (Black, 1953) believe that it is safer in routine practice to withhold it until it can be given orally but it is often impossible to foresee how soon this will be, especially in patients suffering from severe gastro-intestinal disorders. Since they will be receiving solutions containing relatively large amounts of sodium salts in order to ensure replacement of their abnormal losses - a procedure which itself promotes potassium excretion-it may be very important to give some potassium early in the course of treatment in order to avoid a progressive depletion. The dangerous clinical sequelae of potassium depletion are intestinal dilatation and cardiac insufficiency due to muscular dysfunction, which are not quickly reversible by treatment with potassium. Moreover they may be mistaken for direct effects of the disease itself and the potassium depletion overlooked.

The relative benefits and dangers of treatment have to be gauged according to individual circumstance such as the facilities available for frequent re-appraisal. In complicated and prolonged cases of intestinal obstruction, serial estimations of the serum electrolytes may be very helpful in guiding treatment, if the results are available quickly. They are often chiefly of value in giving confidence to proceed with treatment which has already been prescribed.

\section{Treatment of infants and children}

I propose to devote the rest of the space allocated to me in illustrating the treatment of dehydration in infants and children. An interest in this subject is forced 
upon paediatricians because their patients are so susceptible. Dr Widdowson (I957) told us about the relatively greater need for water of infants compared with adults. Deprivation or increased loss therefore affects them very quickly. If, further, the high incidence of congenital abnormalities of the bowel, which cause intestinal obstruction, susceptibility to gastro-enteritis throughout the ist year of life, and great difficulty and consequently frequent delay in reaching a diagnosis of acute abdominal conditions when they affect young children, are considered it will be understood that the treatment of dehydration is an everyday problem in a children's hospital. For this reason, no doubt, much of the pioneer experimental work which lies behind present-day practice, and which has already been referred to today, was carried out by paediatric investigators, notably led by Gamble (1946-7) and Darrow (1945) in North America and by Kerpel-Fronius (1935) in Hungary.

Certain aspects of the treatment of dehydration in childhood, in particular the high intake of fluid which is customary, and which allows for the excretion of large volumes of urine, make it easier and safer than in adults. Experience has shown that this high intake is also well tolerated if given intravenously. It is therefore practicable to supply the estimated daily requirements of sodium and potassium salts in dilute solution without fear of toxicity. Of course, sometimes, as in adults, more concentrated solutions may be indicated for immediate replacement of abnormal losses.

The daily volumes of fluid to be given are estimated according to body size. Weight and, later, age are satisfactory and easy measurements upon which to assess approximate requirements, the volumes given being roughly proportional to surface area and to metabolic rate (Darrow \& Pratt, 1950).

Thus the volumes to be given daily for infants weighing $5^{-1} 5 \mathrm{lb}$. are $75 \mathrm{ml} . / \mathrm{lb} .=150$ $\mathrm{ml} . / \mathrm{kg}$. Those for older children are: up to 2 years of age, $1500 \mathrm{ml}$. ; $2-5$ years, $175^{\circ}$ $\mathrm{ml}$; ; -7 years, $2000 \mathrm{ml}$; 7-10 years, $2500 \mathrm{ml}$., increasing to $3000 \mathrm{ml}$. at 10 years. Individual adjustments are made if the child is very under- or over-weight for his age.

Stage I. Dilute (usually half isotonic) solutions of sodium chloride or partly of sodium chloride and partly of sodium lactate in $5 \%$ dextrose are given as a rapid initial infusion of $20-30 \mathrm{ml}$./1b. body-weight in $3-6 \mathrm{~h}$, or until urine is passed freely. In shock, blood or plasma is given as part of the initial infusion or, if there is a long history of severe vomiting and salt has not been given for replacement, normal saline is given, at least until the levels of sodium and chloride in the serum have been estimated.

Stage 2. The calculated daily volume is usually given as one-fifth isotonic solutions of sodium salts in $5 \%$ dextrose. Potassium salts are added (about $\mathrm{r} \cdot 0 \mathrm{~g} / 0 \cdot 5 \mathrm{l}$. or pt.) to raise the concentration in the solution to about 20 m-equiv./1., an amount which can be used safely without frequent checks on the level in the serum, provided that the urine output is well maintained. Extra volumes are given if the losses are high, more dilute solutions of saline being used if the increased output is by the skin and lungs, and more concentrated ones (e.g. normal saline) to replace copious vomits or aspirations from the upper bowel.

Hypothetical example. Table I shows a simple hypothetical example of the fluids to be given to a baby weighing $5 \mathrm{~kg}$ (about Io $\mathrm{lb}$.) according to this plan. It will be 
Table I. Solutions used to meet the fluid requirements of a hypothetical $5 \mathrm{~kg}$ infant

\begin{tabular}{|c|c|c|c|c|c|c|}
\hline \multirow[b]{2}{*}{$\begin{array}{l}\text { Solution } \\
\text { for infusion }\end{array}$} & \multirow[b]{2}{*}{$\begin{array}{l}\text { Duration of } \\
\text { infusion } \\
\text { (h) }\end{array}$} & \multirow[b]{2}{*}{$\begin{array}{l}\text { Volume } \\
\text { (ml.) }\end{array}$} & \multicolumn{4}{|c|}{ Content } \\
\hline & & & $\begin{array}{l}\text { Sodium } \\
\text { (m-equiv.) }\end{array}$ & $\begin{array}{l}\text { Potassium } \\
\text { (m-equiv.) }\end{array}$ & $\begin{array}{l}\text { Chloride } \\
\text { (m-equiv.) }\end{array}$ & $\begin{array}{c}\mathrm{HCO}_{3} \\
\text { (m-equiv.) }\end{array}$ \\
\hline $\begin{array}{l}\text { Initial: half isotonic } \\
\mathrm{NaCl} \text { in } 5 \% \text { dextrose }\end{array}$ & 4 & 200 & $15 \cdot 4$ & & $15 \cdot 4$ & \\
\hline $\begin{array}{l}\text { Subsequent: one-fifth } \\
\text { isotonic } \mathrm{NaCl}+\text { potassium } \\
\text { acetate }(2.0 \mathrm{~g} / 1 .) \text { in } 5 \% \\
\text { dextrose }\end{array}$ & $\mathrm{m}$ & 800 & 24 & 16 & 24 & I6 \\
\hline Total & & 1000 & $39 \cdot 4$ & 16 & $39 \cdot 4$ & I6 \\
\hline Total/kg body-weight & & 200 & 8 & 3 & 8 & 3 \\
\hline
\end{tabular}

seen that he receives $8 \mathrm{~m}$-equiv. of sodium and 3 of potassium $/ \mathrm{kg}$ body-weight during the initial and first daily $(24 \mathrm{~h})$ infusion. How well are these amounts likely to restore the volume and repair the composition of his body fluids?

Deficits and their replacement. In severe dehydration due to gastro-intestinal disorders, the deficits of electrolytes may be assumed to be of the order of $10 \mathrm{~m}$-equiv./ $\mathrm{kg}$ of both sodium and potassium, and the water loss is about $100 \mathrm{ml} / \mathrm{kg}$, i.e. $10 \%$ of the body-weight. They are very variable even in patients suffering from the same disease.

Data have been obtained from studies of retention during recovery in infants with gastro-enteritis by Darrow (1946) and Darrow, Pratt, Flett, Gamble \& Weise (1949) and in diabetics by Butler (I950). Cooke (I953) considers that the potassium depletion in diarrhoea is about $8-12$, in pyloric stenosis $10-14$, and in diabetic coma $6 \mathrm{~m}$-equiv./kg body-weight.

Table 2 shows the mean deficits (Darrow et al. 1949) for infants with severe gastro-enteritis, compared with the daily amounts they would receive from the

Table 2. Dailv intake/kg body-weight from various repair solutions compared with the average deficits of dehydrated infants with gastro-enteritis

\begin{tabular}{|c|c|c|c|c|c|c|}
\hline \multirow[b]{3}{*}{ Constituent } & & \multicolumn{5}{|c|}{ Intake from repair solutions } \\
\hline & & \multicolumn{2}{|c|}{ Parenterally administered } & \multicolumn{3}{|c|}{ Orally administered } \\
\hline & $\begin{array}{c}\text { Estimated } \\
\text { deficit } \\
\text { I Io }\end{array}$ & $\begin{array}{l}\text { Two-fifths iso- } \\
\text { tonic Darrow's* } \\
\text { in } 5 \% \text { dextrose } \\
220\end{array}$ & $\begin{array}{l}\text { Butler's† } \\
\text { I } 50\end{array}$ & $\begin{array}{l}\text { Darrow'sf } \\
200\end{array}$ & $\begin{array}{l}\text { Human } \\
\text { milk } \\
\text { I50 }\end{array}$ & $\begin{array}{l}\text { Cow's } \\
\text { milk } \\
\text { I } 50\end{array}$ \\
\hline Sodium (m-equiv.) & 8.6 & $9 \cdot 8$ & $4 \cdot 5$ & $4 \cdot 8$ & 0.75 & $4 \cdot 1$ \\
\hline Potassium (m-equiv.) & 10.4 & $2 \cdot 8$ & $3 \cdot 0$ & $5 \cdot 6$ & I. 8 & 6.0 \\
\hline Chlorine (m-equiv.) & $8 \cdot 3$ & $8 \cdot 3$ & $3 \cdot 3$ & $4 \cdot 8$ & I $\cdot 5$ & $4 \cdot 9$ \\
\hline $\mathrm{HCO}_{3}$ (from lactate) & & $4 \cdot 3$ & $3 \cdot 0$ & $5 \cdot 4$ & & \\
\hline
\end{tabular}

*Govan \& Darrow (1946). †Butler (1949). †Flett, Pratt \& Darrow (1949).

multi-electrolyte solutions recommended for treating this disease. It can be seen that the whole sodium deficit, or nearly so, will be replaced within the first $24 \mathrm{~h}$ of treatment, but that it will usually take much longer to repair the potassium deficit, 
even if the output is small during the course of treatment. Fluids by mouth and especially cow's milk will increase the amount of potassium available for repair.

The multi-electrolyte solutions devised by Darrow (Govan \& Darrow, I946; Flett, Pratt \& Darrow, I949) and Butler, Talbot, Crawford, MacLachlan \& Appleton (I946) may be very useful in simplifying the treatment of a particular disease affecting a well-defined age group, such as infantile gastro-enteritis. But the separate prescription of varying concentrations of sodium salts in dextrose solution, with additions of potassium salts at the appropriate stage of treatment, can be adapted for treating many diseases in patients of all ages, and for this reason has great advantages in the training of doctors and nurses.

Children undergoing abdominal operations. In recent years, at the Queen Elizabeth Hospital, difficulties over the treatment of dehydration have often arisen in children undergoing abdominal operations. It was therefore decided about 3 years ago to treat a series according to the principles which $\mathrm{I}$ have been outlining (Young $\&$ McIntosh, 1957). Ninety-eight survived the immediate operation, and their clinical course was usually smooth, without recurrence of dehydration or signs of overhydration. Three children, who had been given dilute solutions of sodium chloride at the beginning of treatment, developed signs of water intoxication, although preceding losses from the bowel had been high, and probably augmented in the sweat. Experience gained from these patients led to more careful appraisal in subsequent patients with a similar history, who have been given isotonic saline at this stage of treatment, without further instances of water intoxication.

Sixty of the older infants and children were able to tolerate oral feeding within $48 \mathrm{~h}$, but only three of twenty newborns. There remained, therefore, thirty-five with persisting signs of intestinal obstruction requiring replacement of their abnormal losses. Ten (seven newborns) were comfortably maintained on intravenous infusions for periods varying between $I$ and 3 weeks. The test of successful intravenous therapy lies in the incidence of breakdown of water equilibrium amongst patients maintained in this way for a long time. Only three became oedematous, and in two the condition was attributable to cardiovascular disease, and in one to increased abdominal pressure. None developed clinical evidence of potassium depletion. Ten children who had been very dehydrated at the outset were found to have low serum potassium levels during the first $24 \mathrm{~h}$ of treatment, and also six of those with intestinal obstruction of several days' duration, despite the regular daily administration of potassium in the amounts considered to be safe by the intravenous route. If potassium had been omitted, clinical sequelae would probably have developed. Throughout the investigation only one patient has been found to have a high serum potassium level, and this was a newborn infant who was becoming jaundiced.

Dr Black (1957) has drawn attention to the danger of overhydration from administering fluid intravenously just after operation because the kidneys may be under the influence of antidiuretic stimuli at this time. It seems probable that this response to operation is seldom evoked in children. Examination of the urine in twelve consecutive patients during the $24 \mathrm{~h}$ after operation has shown that the output was 
within the expected range and that the specific gravity fell to below $\mathrm{I} \cdot 01 \mathrm{o}$ in all but two, both of whom had high extrarenal losses.

Our observations on this group of children have therefore given us confidence in the present plan of treatment for relieving dehydration successfully, without subsequent breakdown in water equilibrium. Furthermore, it appears to be safe to use it without constant checks on the serum electrolyte levels. Experienced clinical appraisal throughout the period of treatment remains the key-note to success.

\section{REFERENCES}

Black, D. A. K. (1953). Lancet, 264, 353.

Black, D. A. K. (1957). Proc. Nutr. Soc. 16, 123.

Butler, A. M. (1949). Acta paediat., Uppsala, 38, 59.

Butler, A. M. (1950). New Engl. F. Med. 243, 648.

Butler, A. M., Talbot, N. B., Crawford, J. D., MacLachlan, E. A. \& Appleton, J. (1946). Amer. $\mathcal{F}$. Dis. Child. 72, 481.

Cooke, R. E. (1953). Postgrad. Med. 14, 257.

Darrow, D. C. (1945). New. Engl. F. Med. 233, 91 .

Darrow, D. C. (1946). F. Pediat. 28, 515.

Darrow, D. C. \& Pratt, E. L. (1950). F. Amer. med. Ass. 143, 432.

Darrow, D. C., Pratt, E. L., Flett, J. Jr., Gamble, A. H. \& Weise, H. F. (r949). Pediatrics, N.Y., 3, 129.

Elkinton, J. R. (1957). Proc. Nutr. Soc. 16, I I3.

Flett, J. Jr., Pratt, E. L. \& Darrow, D. C. (1949). Pediatrics, N.Y., 4, 604.

Gamble, J. L. (1946-7). Harvey Lect. 42, 247.

Govan, C. D. Jr. \& Darrow, D. C. (1946). F. Pediat. 28, 54 I.

Kerpel-Fronius, E. (1935). Z. Kinderheilk. 57, 489 .

Robinson, J. R. (1957). Proc. Nutr. Soc. 16, 108.

Widdowson, E. M. (1957). Proc. Nutr. Soc. I6, I 18.

Young, W. F. \& McIntosh, J. (I957). To be published. 